\title{
The possible link between the elevated serum levels of neurokinin A and anti-ribosomal $P$ protein antibodies in children with autism
}

\author{
Gehan A Mostafa, ${ }^{1,{ }^{*}}$ and Laila Y AL-Ayadhi ${ }^{1}$
}

\begin{abstract}
Background: Neurogenic inflammation is orchestrated by a large number of neuropeptides. Tachykinins (substance $\mathrm{P}$, neurokinin A and neurokinin B) are pro-inflammatory neuropeptides that may play an important role in some autoimmune neuroinflammatory diseases. Autoimmunity may have a role in the pathogenesis of autism in some patients. We are the first to measure serum neurokinin A levels in autistic children. The relationship between serum levels of neurokinin A and anti-ribosomal P protein antibodies was also studied.

Methods: Serum neurokinin A and anti-ribosomal P protein antibodies were measured in 70 autistic children in comparison to 48 healthy-matched children.

Results: Autistic children had significantly higher serum neurokinin A levels than healthy controls $(P<0.001)$. Children with severe autism had significantly higher serum neurokinin A levels than patients with mild to moderate autism $(P<0.001)$. Increased serum levels of neurokinin $A$ and anti-ribosomal $P$ protein antibodies were found in $57.1 \%$ and $44.3 \%$, respectively of autistic children. There was significant positive correlations between serum levels of neurokinin $A$ and anti-ribosomal $P$ protein antibodies $(P=0.004)$.

Conclusions: Serum neurokinin A levels were elevated in some autistic children and they were significantly correlated to the severity of autism and to serum levels of anti-ribosomal P protein antibodies. However, this is an initial report that warrants further research to determine the pathogenic role of neurokinin A and its possible link to autoimmunity in autism. The therapeutic role of tachykinin receptor antagonists, a potential new class of antiinflammatory medications, should also be studied in autism.
\end{abstract}

Keywords: Anti-ribosomal P protein antibodies; autism, autoimmunity, neurokinin A

\section{Background}

Neurogenic inflammation encompasses a series of vascular and non-vascular inflammatory responses, triggered by the activation of primary sensory neurons, with a subsequent release of inflammatory neuromediators. This results in a neurally mediated immune inflammation $[1,2]$. Neuromediators are mainly released from neurons. Immune and/or structural cells are secondary sources of these mediators during immune inflammation

\footnotetext{
* Correspondence: hafezg@softhome.net

'Autism Research and Treatment Center, AL-Amodi Autism Research Chair, Department of Physiology, Faculty of Medicine, King Saud University, Riyadh, Saudi Arabia

Full list of author information is available at the end of the article
}

$[3,4]$. Neuromediators include neurotrophins and neuropeptides [4].

Neurogenic inflammation is orchestrated by a large number of neuropeptides mainly including tachykinins. Tachykinins (substance P, neurokinin A and neurokinin B) have been considered as a group of neuropeptides which are released from the excitatory part of the nonadrenergic, noncholinergic excitatory nervous system nerves after exposure to allergens. The biological activity of tachykinins depends on their interaction with three specific tachykinin receptors, neurokinin (NK)1 (specific for substance P), NK2 (specific for neurokinin A) and NK3 (specific for neurokinin B) receptors [5-7]. Tachykinin receptor antagonists are a potential new class of

\section{Biomed Central}


anti-inflammatory medicaions in immune-mediated diseases [8-10].

Autoimmunity may have a role in the pathogenesis of autism in a subgroup of patients. This may be indicated by the presence of brain-specific auto-antibodies in some autistic children [11-17]. There is also an increase in the frequency of autoimmune disorders among autistic families [18-23]. Inspite of the fact that the origins of autoimmunity in autism are unknown, the major histocompatibility complex genes and their products might be involved [21,24,25].

Anti-ribosomal P protein antibodies are one group of potentially pathogenic autoantibodies that has a specificity for the functional center of the ribosomal $\mathrm{P}$ proteins which is a family of highly conserved acidic phosphoproteins primarily located on the stalk of the large (60 s) ribosomal subunit [26]. They bind 3 ribosomal proteins identified as P0, P1 and P2 (38, 19 and 17-kDa, respectively) by recognizing a certain epitope found in those 3 proteins. Several possible pathogenic mechanisms for these antibodies in some autoimmune diseases include their binding to epitopes on the cell membrane surface, intracellular penetration, inhibition of protein synthesis, production of pro-inflammatory cytokines and cell apoptosis [27].

Evidence for an interaction between chronic inflammation in autoimmune diseases and neural dysfunction points to an involvement linking the nervous and the immune system. In this context, neuropeptides, including tackykinins and neurotrophins have been recognized as key mediators of neuro-immune interactions in some autoimmune diseases [28]. Thus, investigations regarding the development of pharmacological compounds specifically targeting these molecules could be of interest [29].

This study was the first to measure serum neurokinin A levels in a group of autistic children. The relationship between serum levels of neurokinin A and anti-ribosomal $\mathrm{P}$ protein antibodies was also studied.

\section{Methods}

\section{Study population}

This cross-sectional study was conducted on 70 children who had autism. They were recruited from the Autism Research and Treatment Center, Faculty of Medicine, King Saud University, Riyadh, Saudi Arabia. Patients were fulfilling the criteria of the diagnosis of autism according to the $4^{\text {th }}$ edition of the Diagnostic and Statistical Manual of Mental Disorders [30]. The autistic group comprised 55 males and 15 females. Their ages ranged between 4 and 12 years (mean $\pm \mathrm{SD}=8.10 \pm$ 2.52 years).

Exclusions criteria:
1- Patients who had associated neurological diseases (such as cerebral palsy and tuberous sclerosis) and metabolic disorders (eg. Phenylketonuria) were excluded form the study.

2- Patients with associated allergic, inflammatory or autoimmune disorders.

3- Patients who were receiving any medications.

The control group comprised 48 age- and sexmatched apparently healthy children (37 males and 11 females). They were the healthy older siblings of the healthy infants who attend the Well Baby Clinic, King Khalid University Hospital, Faculty of Medicine, King Saud University, Riyadh, Saudi Arabia for routine following up of their growth parameters. The control children were not related to the children with autism, and demonstrated no clinical findings suggestive of immunological or neuropsychiatric disorders. Their ages ranged between 6 and 11 years (mean $\pm S D=8.79 \pm 2.89$ years).

The local Ethical Committee of the Faculty of Medicine, King Saud University, Riyadh, Saudi Arabia, approved this study. In addition, an informed written consent of participation in the study was signed by the parents or the legal guardians of the studied subjects.

\section{Study measurements}

\section{Clinical evaluation of autistic patients}

This was based on clinical history taking from caregivers, clinical examination and neuropsychiatric assessment. In addition, the degree of the disease severity was assessed by using the Childhood Autism Rating Scale (CARS) [31] which rates the child on a scale from one to four in each of fifteen areas (relating to people; emotional response; imitation; body use; object use; listening response; fear or nervousness; verbal communication; non-verbal communication; activity level; level and consistency of intellectual response; adaptation to change; visual response; taste, smell and touch response and general impressions). According to the scale, children who have scored 30-36 have mild to moderate autism (n $=34$ ), while those with scores ranging between 37 and 60 points have a severe degree of autism $(n=36)$.

\section{Serum assessment of neurokinin A}

Serum levels of neurokinin A were evaluated with an enzyme-linked immunosorbent assay (ELISA) kit which is highly sensitivie to neurokinin A. Neurokinin A like immunoreactivity was measured using an antibody that has originally been isolated from porcine spinal cord. It shows $100 \%$ cross reactivity to neurokinin A with little reactivity to other tachykinins (Peninsula laboratories, 611 Talorwat, Belmont, CA, USA). To increase accuracy, all samples were analysed twice in two independent experiments to assess the interassay variations and to 
ensure reproducibility of the observed results $(\mathrm{P}>0.05)$. No significant cross-reactivity or interference was observed.

Measurement of serum anti-ribosomal $P$ protein antibodies Serum total IgG and IgM anti-ribosomal P protein antibodies were measured by ELISA using ribosomal $\mathrm{P}$ peptide-bovine serum albumin conjugate as an antigen (Nunc immuno module F8 maxisorp; Nunc. Roskilde, Denmark). To increase accuracy, all samples were analysed twice in two independent experiments to assess the interassay variations and to ensure reproducibility of the observed results $(\mathrm{P}>0.05)$. No significant crossreactivity or interference was observed.

\section{Statistical analysis}

The results were analyzed by commercially available software package (Statview, Abacus concepts, inc., Berkley, CA, USA). The data were non-parametric, thus they were presented as median and interquartile range (IQR), which are between the $25^{\text {th }}$ and $75^{\text {th }}$ percentiles. MannWhitney test was used for comparison between these data. Chi-square test was used for comparison between qualitative variables of the studied groups. Spearman's rho correlation coefficient " $r$ " was used to determine the relationship between different variables. For all tests, a probability $(\mathrm{P})$ of less than 0.05 was considered significant. Patients were considered to have elevated serum neurokinin A or anti-ribosomal P protein antibodies if their levels were above the highest cut-off values (107.4 $\mathrm{pg} / \mathrm{ml}$ and 92 units $/ \mathrm{ml}$, respectively) which were the $95^{\text {th }}$ percentiles of serum neurokinin $\mathrm{A}$ and anti-ribosomal P levels, respectively of healthy controls as the distribution of the data was non-parametric.

\section{Results}

Serum Neurokin A levels in autistic children and their relation to the degree of the severity of autism

Autistic children had significantly higher serum neurokinin A levels than healthy controls, $\mathrm{P}<0.001$ (table 1 ). Increased serum neurokinin A levels were found in $57.1 \%(40 / 70)$ of autistic patients.

Patients with severe autism had significantly higher serum neurokinin A levels than children with mild to moderate autism, $\mathrm{P}<0.001$ (table 1 ). Also, the frequency of increased serum neurokinin A levels was significantly higher in children with severe autism (31/ 36: $77.5 \%$ ) than patients with mild to moderate autism (9/34: $26.5 \%), \mathrm{P}<0.001$. Moreover, there were significant positive correlations between serum levels of neurokinin $\mathrm{A}$ and CARS in autistic patients, $\mathrm{P}<0.001$ (Figure 1).

Male and female autistic children had comparable values of serum neurokinin $\mathrm{A}(\mathrm{P}=0.52)$. In addition, serum neurokinin A levels had no significant correlations with the age of the children with autism ( $\mathrm{P}=$ 0.68).

The relationship between the elevated serum levels of neurokinin $A$ and anti-ribosomal $P$ protein antibodies in autistic children

Increased serum levels of anti-ribosomal $\mathrm{P}$ protein antibodies were found in $44.3 \%$ (31/70) of autistic patients. Patients with elevated serum neurokinin A levels had significantly higher serum levels of anti-ribosomal $\mathrm{P}$ protein antibodies [median (IQR): 115 (467) U/ml) than patients with normal serum neurokinin A levels [median (IQR): $23.5(248) \mathrm{U} / \mathrm{ml}), \mathrm{P}=0.02$. In addition, there were significant positive correlations between serum levels of neurokinin $\mathrm{A}$ and anti-ribosomal $\mathrm{P}$ protein antibodies in autistic patients, $\mathrm{P}=0.004$ (Figure 2).

\section{Discussion}

Tachykinins are traditionally viewed as neuropeptides with well-defined functions as neurotransmitters. Tachykinin peptides have also an impact on the function of the immune system [32].

In our series, autistic children had significantly higher serum neurokinin A levels than healthy controls, $\mathrm{P}<$ 0.001. Increased serum neurokinin A levels were found in $57.1 \%$ of autistic patients. We could not trace data in the literature concerning neurokinin A levels in the blood of autistic patients to compare our results. This study was the first to investigate serum neurokinin A levels in autistic children.

In a recent study some neuropeptides were investigated in autistic children. It reported increased serum levels of neurotensin, while the other studied neuropeptides $(\beta$-endorphin and substance $\mathrm{P})$ were not reported to be increased in these children [33]. Many studies reported that tachykinins may also be produced by non-

Table 1 Serum levels of neurokinin A in autistic children and their relation to the severity of autism.

\begin{tabular}{lcc}
\hline & $\begin{array}{c}\text { Neurokinin A (pg/ml) } \\
\text { Median (IQR) }\end{array}$ \\
\hline Healthy children $(\mathrm{n}=48)$ & $52.5(31)$ \\
Patients with autism $(\mathrm{n}=70)$ & $130(328)$ \\
Patients with mild to moderate autism $(\mathrm{n}=34)$ & $54.5(78)$ \\
Patients with severe autism $(\mathrm{n}=36)$ & $329(649)$ \\
\hline
\end{tabular}




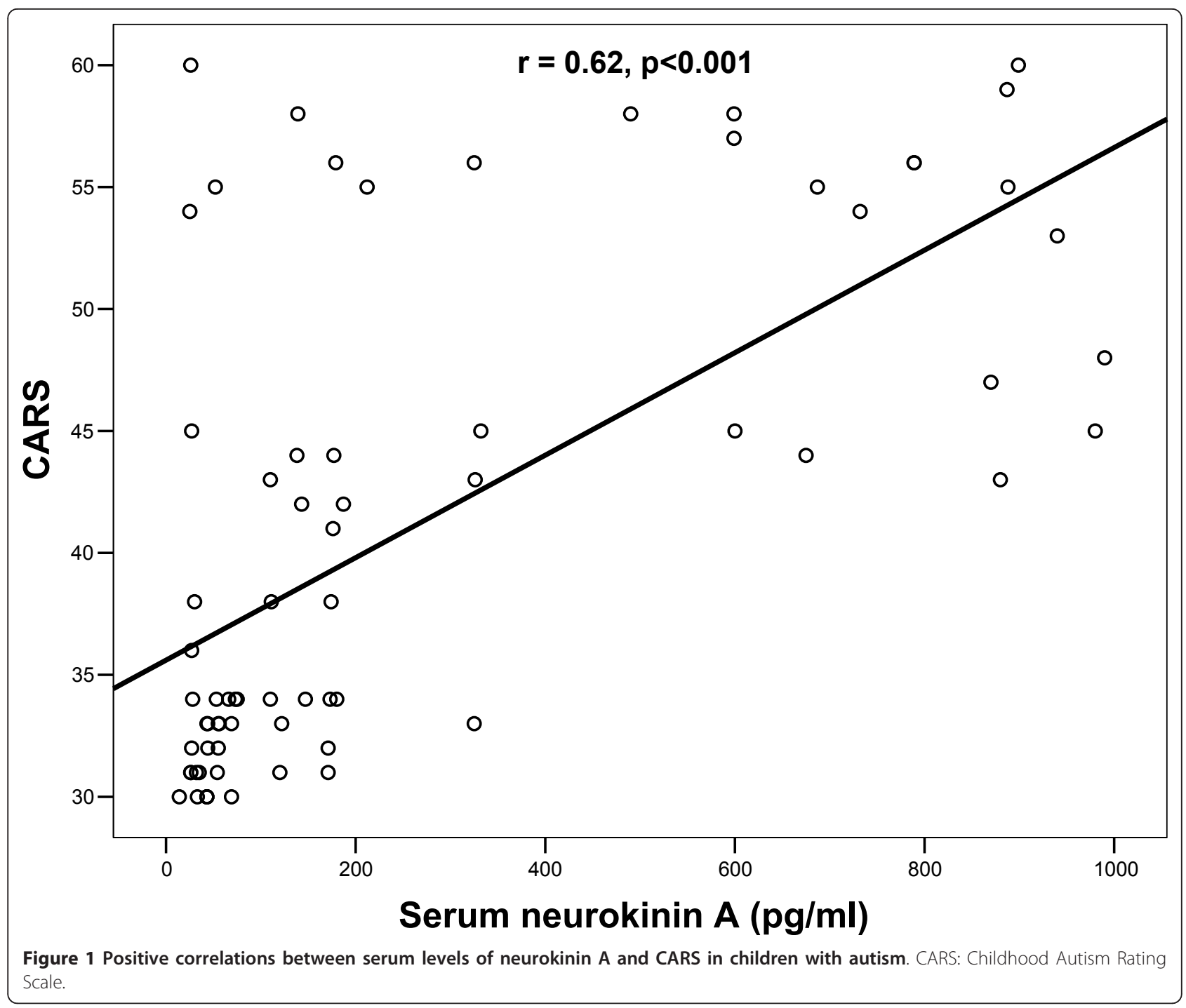

neuronal cells, such as immune cells after exposure to inflammatory stimuli and they exert profound influence on the inflammatory responses by affecting multiple aspects of immune cell function [32]. In one study, the elevated sputum neurokinin A levels had significant positive correlations to eosinophil counts in both blood and sputum of asthmatic children during exacerbation [34]. Thus, the reason behind the increase of serum neurokinin A levels in autistic children may be the stimulation of the immune cells, after exposure to some environmental antigens (such as food allergens, infectious agents and heavy metals), with a subequent increase in the release of this tachykinin from these cells.

Neuroendocrine hormones, including tackykinins, triggered during stress may lead to immune dysregulation resulting from altered cytokine production, resulting in autoimmune or atopic diseases. Thus, the stress response with subsequent induction of a dysregulation of cytokine balance can trigger the hypothalamic-pituitary-adrenal axis and sympathetic nervous system through overproduction of neuropeptides and cytokines. In several autoimmune diseases such as rheumatoid arthritis, systemic lupus erythematosus (SLE), and diabetes mellitus, the immune dysregulation may be attributable to the neuroendocrine-immune network imbalance through overproduction of neuropeptides and cytokines [35]. One member of tachykinins, substance P, was reported to be increased in the cerebrospinal fluid obtained from patients with multiple sclerosis. Similar to autism, multiple sclerosis is an inflammatory disease of the CNS that is generally believed to represent an auto-immunological response to a component of myelin triggered by an environmental factor, in a genetically susceptible individual [36]. Substance P, through NK-1 receptors, contributes to the maintenance of CNS 


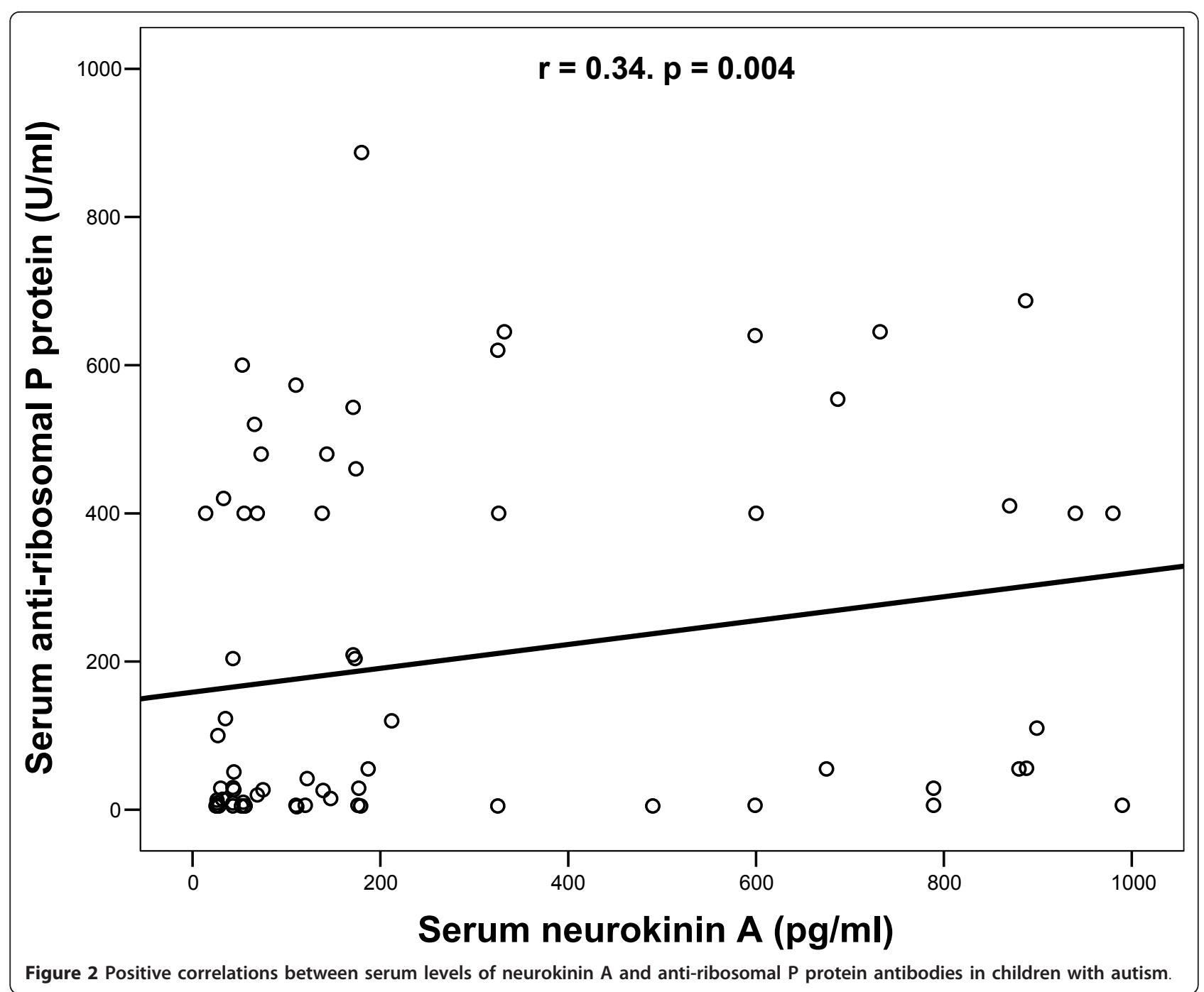

inflammation in multiple sclerosis. NK-1 antagonists, with the conventional anti-inflammatory treatments, may enhance the success of the treatment of some autoimmune diseases such as multiple sclerosis [37].

Tachykinin 1 gene is located in the candidate region for autism and produces substance $\mathrm{P}$ and neurokinins. These products modulate glutamatergic excitatory synaptic transmission and are also involved in inflammation which could be involved in the autistic brain. Therefore, tachykinin 1 gene may have some functions associated with the presumable pathophysiology of autism. To elucidate the genetic background of autism, one study analyzed the relationship between three single nucleotide polymorphisms of the tachykinin 1 gene and autism in the Japanese population, but no significant difference was observed between autistic children and healthy controls [38].

In the present work, patients with severe autism had significantly higher serum neurokinin A levels than children with mild to moderate autism, $\mathrm{P}<0.001$. Also, the frequency of increased serum neurokinin A levels was significantly higher in children with severe autism (77.5\%) than patients with mild to moderate autism (26.5\%), $\mathrm{P}<0.001$. Moreover, there were significant positive correlations between serum levels of neurokinin $\mathrm{A}$ and CARS in autistic patients, $\mathrm{P}<0.001$. This may indicate that the extent of the elevation of serum neurokinin A was closely linked to the degree of the severity of autism. However, it is not easy to determine whether the increase in serum neurokinin A levels is a mere consequence of autism or has a pathogenic role in the disease.

While glial cells are recognized for their roles in maintaining neuronal function, there is a growing evidence of the ability of resident glial cells to initiate and/or augment inflammation following exposure to allergens, trauma or infection in CNS. The tachykinins are found throughout the CNS, with an evidence for both 
neuronal and glial cells as being sources of them. Tachykinins are well known to augment inflammatory responses at peripheral sites, such as the gastrointestinal tract and skin, which raises the possibility that they might serve a similar function within the brain. Tachykinins may have a role in augmenting the immune functions of CNS glial cells resulting in the progression of damaging inflammation within the CNS [39]. Brain mast cells in some autoimmune neuroinflammatory diseases of CNS such as multiple sclerosis are activated by neural factors, including tachykinins. Mast cells can stimulate the activated $\mathrm{T}$ cells coming in contact with them at the blood-brain barrier In addition, brain mast cells secrete numerous proinflammatory and vasoactive molecules that can disrupt the blood-brain barrier, a finding that precedes clinical or pathologic signs of some autoimmune neuroinflammatory diseases of CNS [40].

Autoimmunity to CNS may have a pathogenic role in autism [41-44]. This may be indicated by the presence of brain-specific auto-antibodies in some autistic children [11-17]. In our series, increased serum levels of anti-ribosomal P protein antibodies were found in 44.3\% of autistic patients. This study was the first to investigate serum levels of anti-ribosomal $\mathrm{P}$ protein antibodies in autistic children. Auto antibodies are the hallmark of autoimmune diseases. The reason behind the formation of some auto-antibodies in some patients with autism is not fully understood. It is speculated that autoimmune reaction might be trigged by cross-reacting antigens in the environment resulting in the release of some self antigens. These antigens may result in the induction of autoimmune reactions through the activation of inflammatory cells in genetically susceptible individuals $[41,42]$.

Anti-ribosomal P protein antibodies are highly specific for SLE, especially for the neuropsychiatric manifestations including psychosis, mood disorders, anxiety, cognitive dysfunction and delirium [45]. A recent study has demonstrated a strong association between the seropositivity of anti-ribosomal $\mathrm{P}$ protein antibodies and the presence of neuropsychiatric manifestations in a group of children with SLE [46]. There are some studies in the literature relating anti-ribosomal $\mathrm{P}$ protein antibodies to the pathogenesis of organ damage in SLE. The main pathways described are cross-reaction with anti-dsDNA antibodies, a cytotoxic effect on mesangium cell proliferation, invasion into living cells and starting apoptosis, a defect in the synthesis of apolipoprotein $B$ resulting in accumulation of lipids inside the cell, and downregulation of the total protein synthesis. P proteins are posttranslationally modified (dephosphorylated) during apoptosis, and a dysregulation in the normal clearance of apoptotic cells leads to aberrant exposure of the immune system to modified non self-antigens. This could be one of the triggering events for the development of anti-P autoimmune response in some autoimmune diseases [45].

Moreover, in an experimental study, mice that had been received intra-cerebroventricular injection of antiribosomal $\mathrm{P}$ protein antibodies developed depressionlike behaviors, which seems to be mediated by specific binding of these antibodies to limbic system brain areas, such as hippocampus and cingulate. It has been propsed that anti-ribosomal $\mathrm{P}$ protein antibodies both directly or indirectly affect CNS and produce a cytotoxic effect on neuronal cells. The mechanism by which these antibodies cross the blood brain barrier is unknown [47].

The potential role of neuropeptides in the progression and amplification of the immune neurogenic inflammation is of a great interest. These effects are described by the term immunological plasticity that include enhancement of survival, differentiation, and/or proliferation of immune cells and activation of the release of cytokines or mediators [48]. Therefore, neurogenic inflammation describes a vicious cycle of neuroimmune interactions that amplify immunogenic inflammation and neuropeptides are cross talks between the immune and nervous systems in immunogenic inflammation $[49,50]$.

As neuropeptides were reported to have a possible role in some systemic autoimmune diseases and autoimmune neuroinflammatory diseases [35-37], we have tried to find a possible link between the elevated serum levels of neurokinin A and anti-ribosomal P protein antibodies in autism. In this work, patients with elevated serum neurokinin A levels had significantly higher serum levels of anti-ribosomal $\mathrm{P}$ protein antibodies than patients with normal serum neurokinin A levels, $\mathrm{P}=0.02$. In addition, there were significant positive correlations between serum levels of neurokinin $\mathrm{A}$ and anti-ribosomal $\mathrm{P}$ protein antibodies in autistic patients, $\mathrm{P}=0.004$. We could not trace data in the literature concerning the relationship between serum levels of neurokinin A and auto-antibodies in autistic patients to compare our results. We are the first to study such a relationship. The results of this study may indicate that the elevated serum levels of neurokinin A may be a possible contributing factor to the increased frequency of anti-ribosomal $\mathrm{P}$ protein antibodies in some autistic children. However, this is an initial report that warrants further research to determine the possible link between the elevated serum levels of neurokinin $\mathrm{A}$ and anti-ribosomal $P$ protein antibodies.

After exposure to allergens, inflammatory cell (e.g. eosinophils) derived tachykinins are a major second source of these proinflammatory mediators $[3,4]$ which can alter the function of the immune system [32]. Tachykinins may induce the so called neurogenic inflammation by recruitment and activation of the 
inflammatory cells $[3,4]$. Neuropeptides were reported to have modulatory effects on immune cells, in vivo, especially on T-helper (Th)1/Th2 balance. In addition, neuropeptides can directly stimulate lymphocytes to produce Th2 cytokines, going in line with the Th2 type shifted immune response [51-53]. Th2 cells orchestrate many aspects of pathologic immune responses including effector functions of B-cells, mast cells and eosinophils. These cells produce an array of cytokines such as IL4, IL-5, IL-9 and IL-13. In some autistic children there is an imbalance of $\mathrm{T}$-helper (Th)1/Th2 subsets toward Th2, which are responsible for allergic response and production of antibodies [41].

Thus, the increased seum levels of neurokinin A may explain the increased frequency of anti-ribosomal P protein antibodies in some autistic children as a result of Th2 type shifted immune response. However, these data should be treated with a great caution, until further investigations are performed, as the seropositivity for anti-ribosomal $\mathrm{P}$ protein antibodies in some autistic children may be a mere association with the increased serum levels of neurokinin A in autism. A more detailed understanding of the interactions between tachykinins and immune cells may provide the basis for the development of new therapies for inflammatory and immunemediated diseases [32]. Recent findings point to tachykinergic systems as promising targets of novel clinical agents in many inflammatory diseases [7]. These agents may antagonize NK2 receptors only [8] or may be NK1/ 2 receptor antagonists $[9,10]$

\section{Conclusions}

Serum neurokinin A levels were elevated in some autistic children and they were significantly correlated to the severity of autism and to serum levels of anti-ribosomal $P$ protein antibodies. However, this is an initial report that warrants further research to determine the pathogenic role of neurokinin A and its possible link to autoimmunity in autism. The therapeutic role of tachykinin receptor antagonists, a potential new class of antiinflammatory medications, should also be studied in autism.

\section{Abbreviations \\ (CARS): Childhood Autism Rating Scale; (CNS): central nervous system; (IL): interleukin; (IQR): interquartile range; (Th): T-helper; (SLE): systemic lupus erythematosus.}

\section{Acknowledgements}

This work was financially supported by the King Abdulaziz City for Science and Technology, Riyadh, Saudi Arabia. It was also supported by NPST, Health Research and Studies program at Kind Saud University.

\section{Author details}

'Autism Research and Treatment Center, AL-Amodi Autism Research Chair, Department of Physiology, Faculty of Medicine, King Saud University, Riyadh,
Saudi Arabia. ${ }^{2}$ Department of Pediatrics, Faculty of Medicine, Ain Shams University, Cairo, Egypt.

\section{Authors' contributions}

Both authors designed, performed and wrote the research. In addition, both authors read and approved the final manuscript.

\section{Competing interests}

The authors declare that they have no competing interests.

Received: 8 October 2011 Accepted: 21 December 2011

Published: 21 December 2011

\section{References}

1. Geppetti P, Nassini R, Materazzi S, Benemei S: The concept of neurogenic inflammation. BJU Int 2008, 101(Suppl 3):2-6.

2. Richardson JD, Vasko MR: Cellular mechanisms of neurogenic inflammation. J Pharmacol Exp Ther 2002, 302(3):839-45.

3. Nockher $W A$, Renz $\mathrm{H}$ : Neurotrophins in inflammatory lung diseases: modulators of cell differentiation and neuroimmune interactions. Cytokine Growth Factor Rev 2003, 14:559-78.

4. Micera A, Lambiase A, Bonini S: The role of neuromediators neuromediators in ocular allergy. Curr Opin Allergy Clin Immunol 2008, 8(5):466-71.

5. Maggi CA: The troubled story of tachykinins and neurokinins. Trends Pharmacol Sci 2000, 21:173-175.

6. Almeida TA, Rojo J, Nieto PM, Pinto FM, Hernandez M, Martin JD, et al: Tachykinins and tachykinin receptors: structure and activity relationships. Curr Med Chem 2004, 11:2045-81.

7. Ramalho R, Raquel Soares R, Nuno Couto N, Moreira A: Tachykinin receptors antagonism for asthma: a systematic review. BMC Pulm Med 2011, 11:41.

8. Ettorre A, D'Andrea P, Mauro S, Porcelloni M, Rossi C, Altamura M, et al: hNK2 receptor antagonists. The use of intramolecular hydrogen bonding to increase solubility and membrane permeability. Bioorg Med Chem Lett 2011, 21(6):1807-1809.

9. Sigfridsson K, Ahlqvist M, Lindsjö M, Paulsson S: Early development evaluation of AZD2738, a substrate for the NK receptors. Drug Dev Ind Pharm 2011, 37(6):719-726

10. Sigfridsson K, Ahlqvist M, Carlsson A, Fridström A: Early development evaluation of AZD8081: a substrate for the NK receptors. Drug Dev Ind Pharm 2011, 37(6):702-713, Autoimmunity. 2005; 38(1):85-92.

11. Singh VK, Warren RP, Odell JD, Warren WL, Cole P: Antibodies to myelin basic protein in children with autistic behavior. Brain Behav Immun 1993, 7(1):97-103.

12. Singh VK, Warren RP, Averett R, Ghaziuddin M: Circulating autoantibodies to neuronal and glial filament proteins in autism. Pediatr Neurol 1997. 17(1):88-90.

13. Singh VK, Lin SX, Yang VC: Serological association of measles virus and human herpesvirus-6 with brain autoantibodies in autism. Clin Immunol Immunopathol 1998, 89(1):105-108.

14. Singh VK, Rivas WH: Prevalence of serum antibodies to caudate nucleus in autistic children. Neurosci Lett 2004, 355(1-2):53-56.

15. Mostafa GA, El-Sayed ZA, Abd El Aziz MM, El-Sayed MF: Serum anti-myelinassociated glycoprotein antibodies in Egyptian autistic children. $J$ Child Neurol 2008, 23:1413-1418.

16. Mostafa GA, Al-Ayadhi LY: Increased serum levels of anti-ganglioside M1 auto-antibodies in autistic children: relation to the disease severity. $J$ Neuroinflammation 2011, 8:39.

17. Mostafa GA, Al-Ayadhi LY: A lack of association between hyperserotonemia and the increased frequency of serum anti-myelin basic protein auto-antibodies in autistic children. J Neuroinflammation 2011, 8:71.

18. Comi AM, Zimmerman AW, Frye VH, Law PA, Peeden JN: Familial clustering of autoimmune disorders and evaluation of medical risk factors in autism. J Child Neurol 1999, 14:388-394.

19. Sweeten TL, Bowyer SL, Posey DJ, Halberstadt GM, McDougle CJ: Increased prevalence of familial autoimmunity in probands with pervasive developmental disorders. Pediatrics 2003, 112(5):420-424.

20. Mostafa GA, Kitchener N: Serum anti-nuclear antibodies as a marker of autoimmunity in Egyptian autistic children. Pediatr Neurol 2009, 40:107-112. 
21. Mostafa GA, Shehab A: The link of C4B null allele to autism and to a family history of autoimmunity in Egyptian autistic children. $J$ Neuroimmunol 2010, 223:115-119.

22. Mostafa GA, El-Hadidi ES, Hewedi DH, Abdou MM: Oxidative stress in Egyptian children with autism: relation to autoimmunity. J Neuroimmunol 2010, 219:114-118

23. Mostafa GA, Shehab A AL, Fouad NR: Frequency of $C D 4^{+} \mathrm{CD} 25^{\text {high }}$ regulatoryT cells in the peripheral blood of Egyptian children with autism. J Child Neurol 2010, 25:328-335.

24. Warren RP, Singh VK, Cole P, Odell JD, Pingree CB, Warren WL, White E: Increased frequency of the null allele at the complement $\mathrm{C} 4 \mathrm{~b}$ locus in autism. Clin Exp Immunol 1991, 83:438-440.

25. Odell D, Maciulis A, Cutler A, Warren L, McMahon WM, Coon H, et al: Confirmation of the association of C4B null allele in autism. Human Immunol 2005, 6(2):140-145.

26. Gerli R, Caponi L: Anti-ribosomal P protein antibodies. Autoimmunity 2005, 38(1):85-92

27. Toubi E, Shoenfeld Y: Clinical and biological aspects of anti-P-ribosomal protein autoantibodies. Autoimmun Rev 2007, , 3: 119-125.

28. Veres TZ, Rochlitzer S, Braun A: The role of neuro-immune cross-talk in the regulation of inflammation and remodelling in asthma. Pharmacol Ther 2009, 122(2):203-214.

29. Satake H, Kawada T: Overview of the primary structure, tissuedistribution, and functions of tachykinins and their receptors. Current Drug Targets 2006, 7(8):963-974.

30. American Psychiatric Association: Diagnostic and Statistical Manual of Mental Disorders. Washington DC: American Psychiatric Association ; 4 1994.

31. Schopler E, Reichler RJ, Renner BR: The Childhood Autism Rating Scale (CARS), for Diagnostic Screening and Classification in Autism. New York, NY: Irvington; 1986.

32. Zhang $Y$, Berger $A$, Milne $C D$, Paige $C J$ : Brain Dev. Tachykinins in the immune system. Curr Drug Targets 2006, 7(8):1011-1020.

33. Angelidou A, Francis K, Vasiadi M, Alysandratos KD, Zhang B, Theoharides A et al: Neurotensin is increased in serum of young children with autistic disorder. J Neuroinflammation 2010, 7:48.

34. Mostafa GA, Reda SM, Abd El-Aziz MM, Ahmed SA: Sputum neurokinin A in Egyptian asthmatic children and adolescents: relation to exacerbation severity. Allergy 2008, 9: 1244-1247.

35. Frieri M: Neuroimmunology and inflammation: implications for therapy of allergic and autoimmune diseases. Ann Allergy Asthma Immunol 2003, 90(6 Suppl 3):34-40.

36. Qureshi GA, Baig SM, Parvez SH: Variation in cerebrospinal fluid levels of neuropeptide $Y$, cholecystokinin and substance $P$ in patients with neurological disorders. Neuro Endocrinol Lett 2000, 21(5):409-416.

37. Reinke EK, Johnson MJ, Ling C, Karman J, Lee J, Weinstock JV, et al: Substance $\mathrm{P}$ receptor mediated maintenance of chronic inflammation in EAE. J Neuroimmunol 2006, 180(1-2):117-125.

38. Marui T, Funatogawa I, Koishi $\mathrm{S}$, Yamamoto $\mathrm{K}$, Matsumoto $\mathrm{H}$, Hashimoto $\mathrm{O}$, et al: Tachykinin 1 (TAC1) gene SNPs and haplotypes with autism: a case-control study. Brain Dev 2007, 29(8):510-513.

39. Marriott I: The role of tachykinins in central nervous system inflammatory responses. Front Biosci 2004, 9:2153-65.

40. Theoharides TC, Kempuraj D, Kourelis T, Manola A: Human mast cells stimulate activated T cells: implications for multiple sclerosis. Ann N Y Acad Sci 2008, 1144:74-82.

41. Cohly HH, Panja A: Immunological findings in autism. Int Rev Neurobiol 2005, 71:317-341.

42. Vojdani A, Campbell AW, Anyanwu E, Kashanian A, Bock K, Vojdani E: Antibodies to neuron-specific antigens in children with autism: possible cross-reaction with encephalitogenic proteins from milk, Chlamydia pneumoniae and Streptococcus group A. J Neuroimmunol 2002, 129(1-2): 168-177.

43. Al-Ayadhi LY, Mostafa GA: Low plasma progranulin levels in children with autism. J Neuroinflammation 2011.

44. Al-Ayadhi LY, Mostafa GA: Increased serum osteopontin levels in autistic children: Relation to the disease severity. Brain Behav Immun 2011 25(7):1393-1398.

45. Ben-Ami SD, Blank M, Altman A: The clinical importance of antiribosomal-P antibodies. Harefuah 2010, 149(12):794-797.
46. Mostafa GA, Ibrahim DH, Shehab AA, Mohammed AK: The role of measurement of serum autoantibodies in prediction of pediatric neuropsychiatric systemic lupus erythematosus. J Neuroimmunol 2010, 227(1-2):195-201.

47. Katzav A, Solodeev I, Brodsky O, Chapman J, Pick CG, Blank M, Zhang W, Reichlin M, Shoenfeld Y: Induction of autoimmune depression in mice by anti-ribosomal P antibodies via the limbic system. Arthritis Rheum 2007, 56(3):938-948.

48. Nockher WA, Renz H: Neurotrophins in allergic diseases: From neuronal growth factors to intercellular signaling molecules. J Allergy Clin Immunol 2006, 117:583-589

49. O'Connor TM, O'Connell J, O'Brien DI, Goode T, Bredin CP, Shanahan F: The role of substance P in inflammatory disease. J Cell Physiol 2004, 201:167-80.

50. Renz H, Kerzel S, Nockhe WA: The role of neurotrophins in bronchial asthma: contribution of the pan-neurotrophin receptor p751. Prog Brain Res 2004, 146:325-333.

51. Herberth G, Daegelmann C, Weber A, Röder S, Giese T, Krämer U, et al: Association of neuropeptides with Th1/Th2 balance and allergic sensitization in children. Clin Exp Allergy 2006, 36(11):1408-1416.

52. Herberth G, Daegelmann C, Weber A, Röder S, Giese T, Krämer U, et al: Association of neuropeptides with Th1/Th2 balance and allergic sensitization in children. Clin Exp Allergy 2006, 36(11):1408-1416.

53. Sekimoto M, Tsuji T, Matsuzaki J, Chamoto K, Koda T, Nemoto K, et al: Functional expression of the TrkC gene, encoding a high affinity receptor for NT-3, in antigen-specific T helper type 2 (Th2) cells. Immunol Lett 2003, 88:221-226.

doi:10.1186/1742-2094-8-180

Cite this article as: Mostafa and AL-Ayadhi: The possible link between the elevated serum levels of neurokinin A and anti-ribosomal P protein antibodies in children with autism. Journal of Neuroinflammation 2011 8:180.

\section{Submit your next manuscript to BioMed Central and take full advantage of:}

- Convenient online submission

- Thorough peer review

- No space constraints or color figure charges

- Immediate publication on acceptance

- Inclusion in PubMed, CAS, Scopus and Google Scholar

- Research which is freely available for redistribution 